\section{(6) OPEN ACCESS}

\title{
Notch signalling pathways mediate synovial angiogenesis in response to vascular endothelial growth factor and angiopoietin 2
}

\author{
Wei Gao, Catherine Sweeney, Ceara Walsh, Peadar Rooney, Jennifer McCormick, \\ Douglas J Veale, Ursula Fearon
}

\begin{abstract}
- Additional supplementary data are published online only. To view these files please visit the journal online (http://dx.doi. org/10.1136/annrheumdis2012-201978).
\end{abstract}

Department of Rheumatology, Translational Research Group, Dublin Academic Medical Centre, St Vincent's University Hospital, Dublin, Ireland

\section{Correspondence to}

Dr Ursula Fearon, Department of Rheumatology, Dublin Academic Medical Centre St. Vincent's University Hospital, Dublin 4, Ireland; ursula.fearon@ucd.ie

Accepted 20 October 2012 Published Online First 17 November 2012

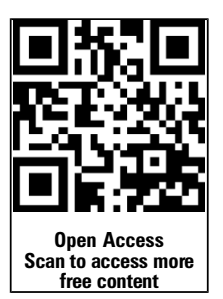

\section{ABSTRACT}

Objective Notch signalling pathways are critical for angiogenesis and endothelial cell (EC) fate; however the mechanisms regulating these processes in the inflamed joint remain to be elucidated. Here, we examine whether Notch signalling mediates vascular endothelial growth factor (VEGF) and angiopoietin 2 (Ang2)-induced vascular function. Methods Notch-1 intracellular domain (Notch-1 IC), Notch-4 IC, Delta-like-ligand 4, Hes-related transcriptional repressors-1 and 2 (Hrt-1, Hrt-2) mRNA and/or protein expression was measured by Real-time PCR and/or western blot. VEGF/Ang2 induced EC function was assessed using transwell invasion chambers, matrigel tube formation assays and wound repair scratch assays \pm Notch-1 siRNA or an $\gamma$-secretase inhibitor N-(N-(3,5-Difluorophenacetyl-Lalanly))-S-phenylglycine-t-Butyl Ester (DAPT) in RA synovial explants or human microvascular EC. Interleukin (IL)-6 and IL- 8 were measured by ELISA and MMP2 and 9 by gelatine zymography.

Results Notch-1 IC and Notch-4 IC protein expressions were demonstrated in RA and psoriatic arthritis synovial biopsies, with minimal expression observed in Osteoarthritis (OA). VEGF and Ang2 induced Notch-1 IC/ Notch-4 IC protein expression in synovial explant cultures and human microvascular EC levels were further potentiated by VEGF/ Ang2 stimulation in combination. Notch-1, Delta-like-ligand 4, and Hrt-2 mRNA expression were significantly induced by VEGF and Ang2 alone and in combination. Furthermore VEGF/Ang2-induced EC invasion, angiogenesis and migration were inhibited by Notch-1 siRNA or DAPT. Conditioned media from VEGF/Ang2 stimulated RA synovial explants induced EC tube formation, an effect that was inhibited by DAPT. Finally, DAPT significantly decreased VEGF/Ang2 induced IL-6, IL-8, MMP2 and 9 expressions in RA synovial explants.

Conclusions Notch-1 mediates VEGF/Ang2-induced angiogenesis and $\mathrm{EC}$ invasion in inflammatory arthritis.

\section{INTRODUCTION}

Inflammatory arthritis (IA) is a progressive autoimmune disease affecting $1 \%$ of the population. ${ }^{1}$ Dysregulated angiogenesis is an early event in IA facilitating synovial membrane (SM) vessel invasion, persistent leukocyte infiltration and lining layer hyperplasia, capable of destroying adjacent cartilage and bone. ${ }^{2-4}$ Vascular endothelial growth factor (VEGF), Angiopoietin (Ang), platelet derived growth factor and transforming growth factor- $\beta$ all regulate vessel stability and induce fibroblast invasion. ${ }^{4-10}$ Furthermore, studies demonstrate similar dysfunctional microvessels in the papillary dermis of skin in Psoriatic arthritis (PsA) patients associated with differential expression of VEGF, Ang1/2, MMP-9 and E-selectin. ${ }^{11-14}$

VEGF stimulates endothelial cell (EC) proliferation, permeability, migration and promotes EC survival. ${ }^{3} 15$ Ang, a family of EC specific factors are also fundamental in vessel formation. ${ }^{16-21}$ Complementary action between VEGF and Ang controls vessel stability and maturation. ${ }^{19-21}$ Ang1 knockout mice are embryo lethal, due to absent capillary sprouts and vessel wall deformity. ${ }^{16}$ Ang1 overexpression increases $\mathrm{EC} /$ pericyte interactions resulting in stable vasculature while angiopoietin 2 (Ang2) antagonises Ang1 on invading vascular sprouts, blocking stabilisation. ${ }^{18-20}$ Differential expression of Ang1, Ang2 and VEGF has been demonstrated in synovial tissue/cells and are associated with differential pathogenic outcomes. 582223 Expression of Ang1, Ang2 and their receptor Tie2 are significantly increased in progression of collagen induced arthritis (CIA), and Tie2 blockade ameliorates bone destruction. ${ }^{24} 25$ Recently, we demonstrated that Tie2 mediates Toll-like receptor-2 induced angiogenesis in Rheumatoid arthritis (RA). ${ }^{26}$

The Notch signalling pathway plays a pivotal role in vascular development, cell-cell communication, cell fate decisions. ${ }^{27-30}$ Notch is also critical for EC-pericyte interactions and vascular network remodelling. ${ }^{28-33}$ Four Notch receptors are described in mammals with ligands encoded by Jagged-1, 2 and Delta-like 1, 3, 4 (DLL-1, DLL-3, DLL-4) genes. ${ }^{34-41}$ Cleavage of Notch receptors releases Notch intracellular domain which translocates into the nucleus, ${ }^{39} 40$ regulating downstream target genes, Hrt (Hes-related transcriptional repressors) and Hes (Hairy/Enhancer of Split). ${ }^{28} 41$ Previous studies have shown Notch and/or its receptors in inflamed SM and synoviocytes. ${ }^{42} 43$ Jagged-1 modulates CIA by regulating $\mathrm{T}$ cell responses. ${ }^{44}$ Notch-1 can mediate TNFo-induced synoviocyte proliferation, ${ }^{42} 45$ and Notch-3 and DLL-1 mediate collagen-specific T-cell activation and altered $\mathrm{T}$ helper cells responses. ${ }^{46}$ However, the mechanisms by which Notch signalling regulates angiogenesis in the inflamed joint remain to be elucidated. In this study we examine if Notch signalling mediates VEGF/Ang2 induced angiogenesis in the inflamed joint using ex vivo synovial explant cultures and microvascular ECs. 


\section{MATERIAL AND METHODS}

\section{Patient recruitment and arthroscopy}

Twenty-nine subjects (10M: 19F) were recruited to this study $(\mathrm{RA}=10 ; \quad \mathrm{Ps} A=10 ; \quad \mathrm{OA}=9)$. Synovial tissue biopsies were obtained at arthroscopy as previously described. ${ }^{47}$ Patients with RA and PsA, fulfilled the American College of Rheumatology 48 and Classification Criteria for Psoriatic Arthritis (CASPAR) ${ }^{49}$ criteria. The median age of the RA patients was 52.84 (27.2680.22) years, the PsA 64.39 (32.27-80.58) years and OA 55.89 (37.22-77.21) years. The median DAS28 for RA patients was 4.565 (1.75-6.23), for PsA 3.625 (2.1-4.92) and OA 4.025 (3.254.05). Fifty per cent of inflammatory patients (RA/PsA) were naive for disease modifying antirheumatic drugs and steroids, others had failed at least one disease modifying antirheumatic drugs. Following institutional approval by the St. Vincent's University Hospital medical research and ethics committee, all patients gave written informed consent. All treatment was fully compliant with the Helsinki Declaration.

\section{Ex vivo synovial explant culture}

To examine the effect of VEGF/Ang2 alone and in combination on Notch-1 intracellular domain (Notch-1 IC) and Notch-4 IC expression an ex vivo whole synovial tissue explant model was established. ${ }^{26}$ RA/PsA synovial explant tissue was sectioned into 96-well-plates (Falcon, Franklin Lakes, New Jersey, USA) in Roswell Park Memorial Institute (RPMI) 1640 supplemented with streptomycin (100 units $/ \mathrm{ml})$ and penicillin $(100$ units $/ \mathrm{ml})$ and cultured with VEGF $(20 \mathrm{ng} / \mathrm{ml})^{50}$ (R\&D systems, Abingdon, UK), Ang2 (250 ng/ml $)^{51}$ (R\&D systems) alone and in combination for $24 \mathrm{~h}$ at $37^{\circ} \mathrm{C}$ in $5 \% \mathrm{CO}_{2}$. Supernatants were harvested and tissue was snap frozen for protein analysis.

\section{Culture of HIMVEC}

Human microvascular ECs (HMVEC) (Lonza, Waterville, Inc, California, USA), were grown in endothelial basal medium (EBM) supplemented with $5 \%$ fetal calf serum (FCS), $0.5 \mathrm{ml}$ human epidermal growth factor (hEGF), $0.5 \mathrm{ml}$ hydrocortisone, $0.5 \mathrm{ml}$ gentamicin, $0.5 \mathrm{ml}$ bovine brain extract (Lonza) and used for experiments between passages 3-8. For Notch-1 IC and Notch-4 IC protein expression, HMVEC were grown to confluence, then cultured in serum reduced EBM for $24 \mathrm{~h}(1 \%$ FCS) before stimulation with VEGF $(20 \mathrm{ng} / \mathrm{ml})$ alone and in combination with Ang2 $(250 \mathrm{ng} / \mathrm{ml})$ for a further $24 \mathrm{~h}$.

\section{Western blot analysis}

Synovial tissue and HMVEC protein lysates were prepared as previously described. ${ }^{52}$ Proteins from synovial tissue lysates and HMVEC were resolved on sodium dodecyl sulfate polyacrylamide gel electrophoresis (SDS-PAGE) prior to transfer onto nitrocellulose membrane (Amersham Biosciences, Buckinghamshire, UK). Rabbit polyclonal anti Notch-1 or Notch-4 (Millipore, Temecula, California, USA) were used as previously described. ${ }^{52}$ Blots were developed using enhanced chemiluminescence (ECL) (Pierce, Rockford, Illinois, USA) and signal intensity was quantified by densitometry using the Electrophoresis Documentation and Analysis System (EDAS) 120 system (Kodak, Rochester, New York, USA). Full-length Notch-1 (300 kDa) and extracellular fragment $(200 \mathrm{kDa})$ were also observed in addition to cytoplasmic domain $(120 \mathrm{kDa})$ as per the manufacturer's instructions.

\section{Immunohistochemistry}

Immunohistochemical analysis for Notch-1 and Notch-4 in RA, PsA and OA tissue was performed as previously described ${ }^{52}$ Briefly sections were incubated with primary antibodies against rabbit-polyclonal Notch-1, Notch-4 (Millipore) and isotype matched rabbit-polyclonal IgG control (DAKO, UK) at room temperature for $1 \mathrm{~h}$. Colour was developed in solution containing diaminobenzadine-tetrahydrochloride (Sigma), $0.5 \% \mathrm{H}_{2} \mathrm{O}_{2}$ in phosphate buffered saline (PBS) buffer $(\mathrm{pH}$ 7.6). Slides were counterstained with haematoxylin and mounted. Slides were analysed using a well-established semiquantitative scoring method. ${ }^{52} 53$

\section{Notch-1 siRNA gene silencing studies}

For each $25 \mathrm{~cm}^{2}$ flask of HMVEC transfected, $5 \mu l$ of $20 \mathrm{pmol}$ gene-specific siRNA duplexes (Notch-1 or Scramble) and $5 \mu \mathrm{l}$ of Lipofectamine 2000 Reagent (Invitrogen, BioSciences Ltd., Ireland) were mixed gently with $0.99 \mathrm{ml}$ serum/antibiotic-free Optimal Minimal Essential Medium (OPTI-MEM) (Invitrogen) and incubated at room temperature for 20-30 min in the dark. The combination was mixed with full (5\% FCS) EBM, added to cells and incubated overnight. The siRNA duplexes for Notch-1 (5459NM-017617) and Scrambled control (a nonsense siRNA of the target sequence) were from Sigma.

\section{$\gamma$-Secretase inhibitor (DAPT) studies}

For $\gamma$-secretase inhibitor study, biopsies were sectioned into 96-well-plates and HMVEC were plated in 48-well-plates. Cells were cultured with VEGF $(20 \mathrm{ng} / \mathrm{ml})$, Ang2 $(250 \mathrm{ng} / \mathrm{ml})$ alone and in combination in the presence or absence of $\mathrm{N}-(\mathrm{N}-(3,5-$ Difluorophenacetyl-L-alanly))-S-phenylglycine-t-Butyl Ester (DAPT) (Sigma) used at between 1-50 $\mu$ M, or Dimethyl sulfoxide (DMSO) vehicle control. The supernatants (conditioned media) were harvested for cytokines and tube formation analysis.

mRNA extraction and analysis

HMVEC were grown to confluence, cultured in serum reduced EBM for $24 \mathrm{~h}(1 \% \mathrm{FCS})$ and then stimulated with VEGF $(20 \mathrm{ng} / \mathrm{ml})$ alone and in combination with Ang2 (250 ng/ml) for 3, 6 and $24 \mathrm{~h}$. Total RNA was isolated using RNeasy Mini Kit (Oiagen, Crawley, UK) according to the manufacturer's specifications. Purity of RNA was measured and samples with a ratio over $1.8(260: 280 \mathrm{~nm})$ used in subsequent experiments. Total RNA $(1-2 \mu \mathrm{g})$ was reverse transcribed to cDNA. Relative quantification of gene expression was analysed with preoptimised conditions using Lightcycler-480 PCR technology (Roche Diagnostics, Lewes, UK). Specific primers for Notch-1 (Hs00413187_ml), Hrt-1 (Hs01114113_ml), Hrt-2 (Hs00232622_ml) and DLL-4 (Hs00184092_ml) were used and primers for 18S (Hs99999901_sl) ribosomal RNA were used as an endogenous control (Applied Biosystems, Cheshire, UK).

\section{Invasion assay}

HMVEC invasion was assayed in Transwell Matrigel Invasion Chambers (BD Biosciences, Oxford, UK). HMVEC $\left(3 \times 10^{4}\right.$ cells) transiently transfected with Notch-1 siRNA or scrambled control siRNA were added to invasion chambers on precoated matrigel membranes containing EBM supplemented with 2.5\% FCS. EBM containing 5\% FCS was placed in the lower wells of the assay. Cells were stimulated with VEGF $(20 \mathrm{ng} / \mathrm{ml})$ and Ang2 $(250 \mathrm{ng} / \mathrm{ml})$ alone and in combination for $16 \mathrm{~h}$. Invasion quantification was assessed as previously described. ${ }^{26}$

Tube formation and cell migration assays

Matrigel $(50 \mu \mathrm{l})$ (Becton Dickinson, Franklin Lakes, New Jersey, USA) was added to 96-well culture plates and allowed to polymerise at $37^{\circ} \mathrm{C}$ for $1 \mathrm{~h}$ before plating the cells. HMVEC 
$\left(1 \times 10^{4}\right.$ cells $)$ transiently transfected with Notch- 1 siRNA or scrambled Notch-1 control siRNA were then plated in $250 \mu \mathrm{l}$ $\mathrm{EBM} /$ well onto the surface of the matrigel and stimulated with $\operatorname{VEGF}(20 \mathrm{ng} / \mathrm{ml})$ and Ang2 $(250 \mathrm{ng} / \mathrm{ml})$ alone and in combination for $24 \mathrm{~h}$. Furthermore to examine the effect of the synovial microenvironment on EC function, HMVEC were cultured with conditioned media from stimulated synovial explant cultures VEGF, Ang2 alone and in combination \pm DAPT for $24 \mathrm{~h}$. HMVEC tubes formation was quantified as previously described. ${ }^{26}$ Wound scratch migration assays were also performed as previously described. ${ }^{54}$

\section{Cytokine measurements}

Interleukin (IL)-6 and IL-8 expression in RA explant cultured supernatants was measured by ELISA according to the manufacturer's instructions (R\&D systems).
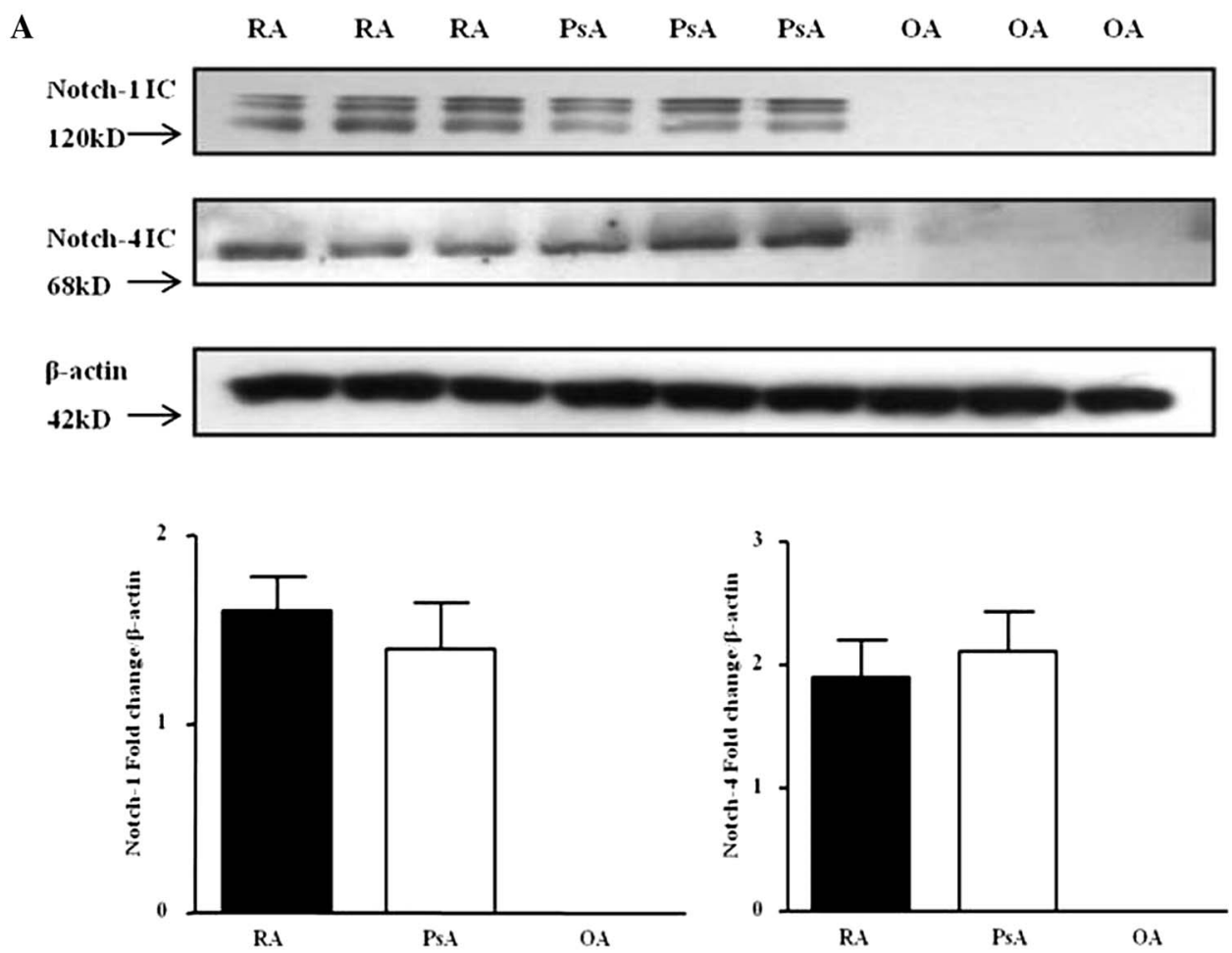

B


$\beta$-actin
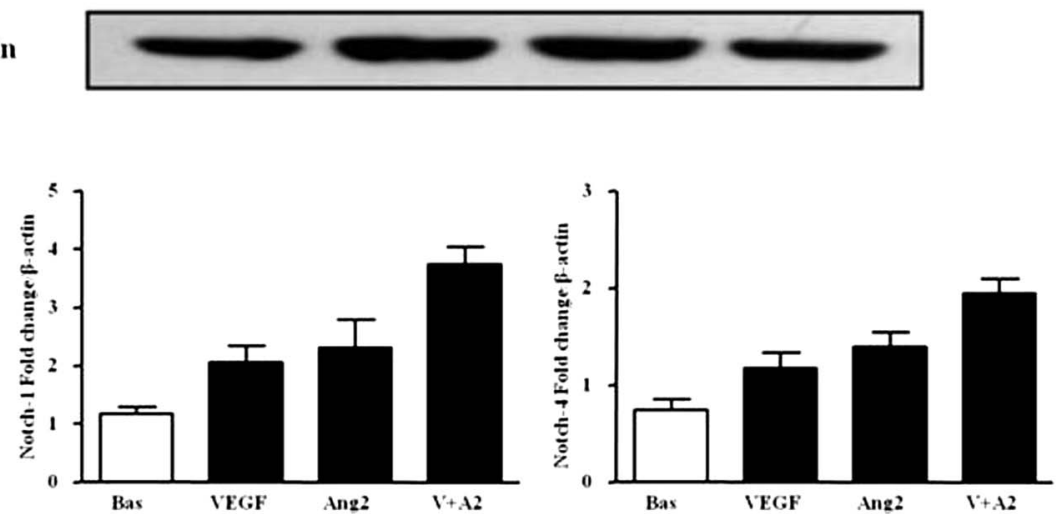

Figure 1 Vascular endothelial growth factor (VEGF) and angiopoietin 2 (Ang2) regulate Notch protein expression in synovial explant cultures. (A) Notch-1 intracellular domain (Notch-1 IC) and Notch-4 IC protein expression were analysed using Western blot in synovial tissues biopsies obtained from RA $(n=7)$, psoriatic arthritis $(n=7)$ and OA $(n=6)$ patients. $\beta$-actin was used as loading control. (B) Notch-1 IC and Notch-4 IC protein expression was examined in ex vivo RA synovial explants cultures following stimulation with VEGF ( $20 \mathrm{ng} / \mathrm{ml})$ and Ang2 (250 ng/ml) alone or in combination for $24 \mathrm{~h}$. $\beta$-actin was used as loading control. Representative blot of $n=3$ experiments performed in triplicate. 
Activities of MIMP-9 and MIMP-2 by zymography

MMP-2 and MMP-9 expression in synovial explants and HMVEC supernatants were measured using gelatin zymography $(6 \mathrm{mg} / \mathrm{ml}) .10 \mu \mathrm{l}$ of supernatants were loaded onto $7.5 \%$ polyacrylamide gels. Following electrophoresis, gels were washed with $2.5 \%$ Triton X-100 and incubated with substrate buffer at $37^{\circ} \mathrm{C}$ for $24 \mathrm{~h}$ prior to Coomassie brilliant blue stain and destained with water.

\section{Statistical analysis}

SPSS V.15 system for windows was used for statistical analysis. For comparisons of multiple groups analysis of variance (ANOVA) with Dunnett post-test for parametric data or the Friedman test with Dunns post-test for non-parametric data was performed. Non-parametric Wilcoxon Signed Rank test for related samples or Parametric Student $t$ tests were performed as appropriate for comparison of two experimental conditions. $p<0.05$ were considered significant.

\section{RESULTS}

Upregulation of Notch signalling by VEGF and Ang2

Protein expression of Notch-1 IC $(120 \mathrm{kD})$ and Notch-4 IC $(68 \mathrm{kD})$ were detected in RA and PsA tissue lysates, with minimal expression observed for $\mathrm{OA}$ tissue (figure $1 \mathrm{~A}$; online supplementary figure S1). Notch-1 IC and Notch-4 IC expression was demonstrated in the synovial perivascular/vascular, sublining layer and lining layer regions in RA (figure 2Ai, ii) and PsA tissue (figure 2Aiii, iv), with minimal expression observed in $\mathrm{OA}$ (figure $2 \mathrm{Av}$, vi). No expression for IgG control was observed (figure 2Avii, viii). Semiquantification demonstrated a significant increase in Notch-1 IC and Notch-4 IC expression in RA and PsA patients compared with OA $(\mathrm{p}<0.05)$ (figure 2B). Furthermore Notch-1 IC and Notch-4 IC expression in the vascular regions was significantly higher in PsA compared with RA $(p<0.05)$ (figure $2 B$ ).

VEGF and Ang2 alone induced Notch-1 IC and Notch-4 IC protein expression, while VEGF/Ang2 combination further increased their expression compared with either VEGF or Ang2 alone (figure 1B). A similar response was observed for PsA explants (see online supplementary figure S2A).

In HMVEC, VEGF and Ang2 alone and in combination induced Notch-1 IC and Notch-4 IC protein expression (figure 3A). Gene expression of Notch-1 receptor, downstream target genes Hrt-1, Hrt-2 and ligand DLL-4 were assessed at 3, 6 and $24 \mathrm{~h}$, with significant induction observed only at $24 \mathrm{~h}$ (figure 3B). VEGF and Ang2 stimulation alone significantly induced DLL-4 and Hrt-2 mRNA $(p<0.05)$, with the combination of VEGF/Ang2 further potentiating the expression of Notch-1, its ligand DLL-4 and Hrt-2 (all $\mathrm{p}<0.05$ ). No significant effect was observed for Hrt-1 (figure 3B).

\section{Notch-1 mediates VEGF/Ang2 induced EC invasion} and tube formation

Notch-1 siRNA (siN1) transfection resulted in minimal detectable levels of Notch-1 IC compared with scramble control (see online supplementary figure S2B) and dramatically inhibited VEGF-induced expression (see online supplementary figure S2C). Furthermore Notch-1 IC protein expression in HMVEC was significantly decreased in the presence of DAPT (see online supplementary figure S2D).

Figure 4A,B shows representative images and quantification of HMVEC invasion demonstrating significant EC invasion in response to VEGF and Ang2 alone, which was further potentiated by VEGF/Ang2 combination. This effect was significantly
A
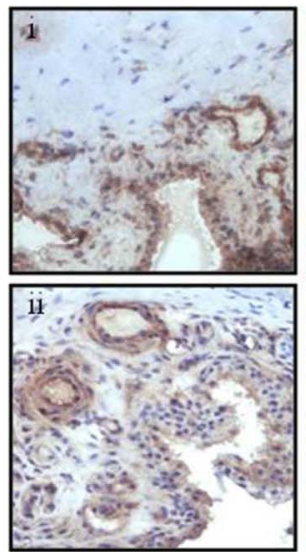
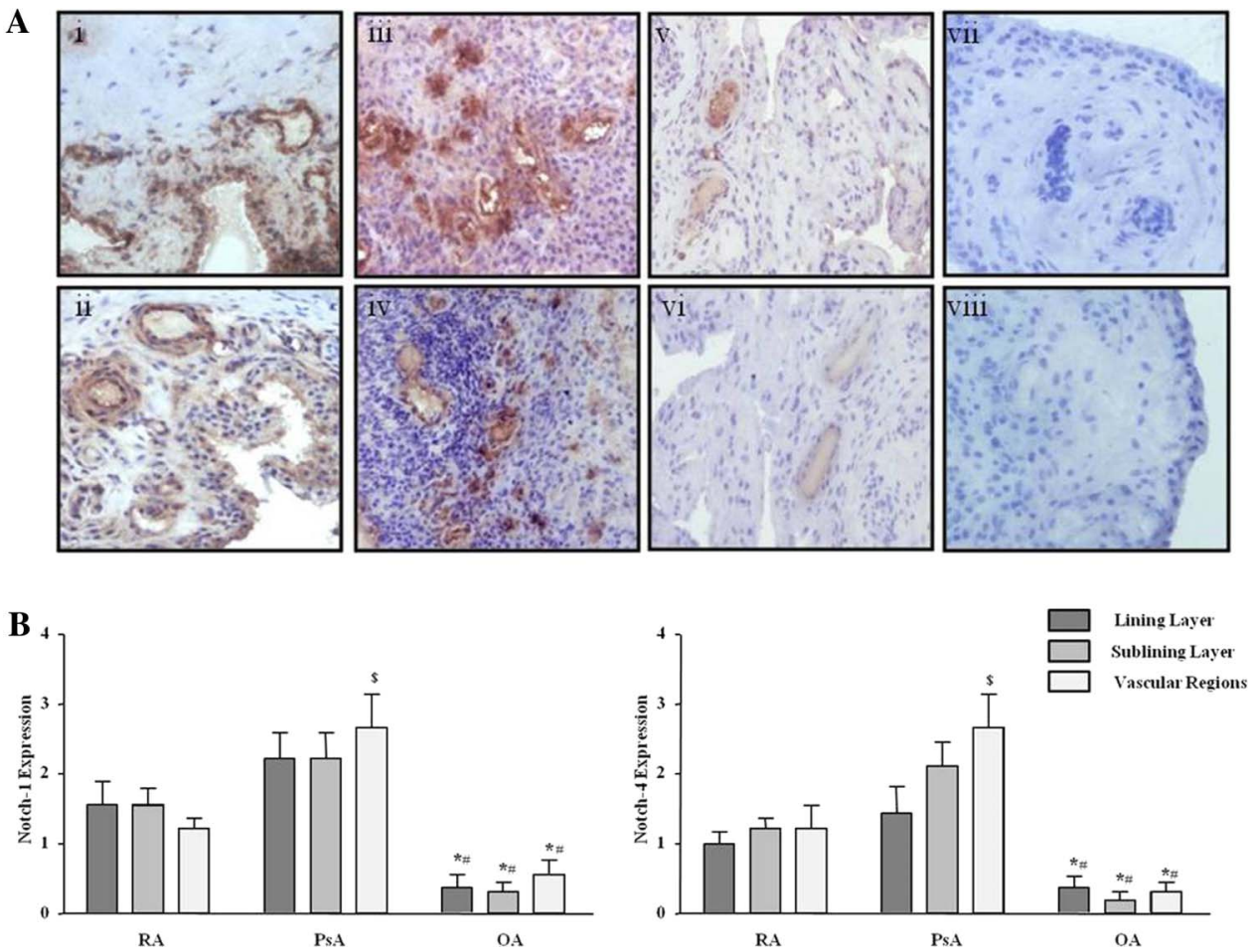

Figure 2 Notch-1 and Notch-4 localised expression in RA, psoriatic arthritis (PsA) and OA patients. (A) Representative photomicrographs showing Notch-1 and Notch-4 localised expression in synovial tissue from RA $(n=10)$, PsA $(n=10)$ and OA $(n=9)$ patients. Notch-1 and Notch-4 expression are shown in RA tissue (i, ii), PsA (iii, iv), OA (v, vi) respectively. Negative staining for IgG control (vii, viii). (B) Quantification of Notch-1 and Notch-4 in lining, sublining and perivascular regions of RA, PsA and OA tissue. ${ }^{*} p<0.050 A$ significantly different from $R A,{ }^{\#} p<0.050 A$ significantly different from PsA, $\$ p<0.05$ PsA significantly different from RA. Original magnification $\times 10$. 
A

Bas VEGF Ang2 VEGF+Ang2 Notch-1IC

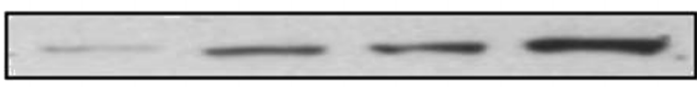

Notch-4IC

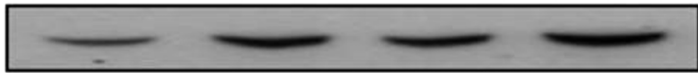

$\beta$-actin
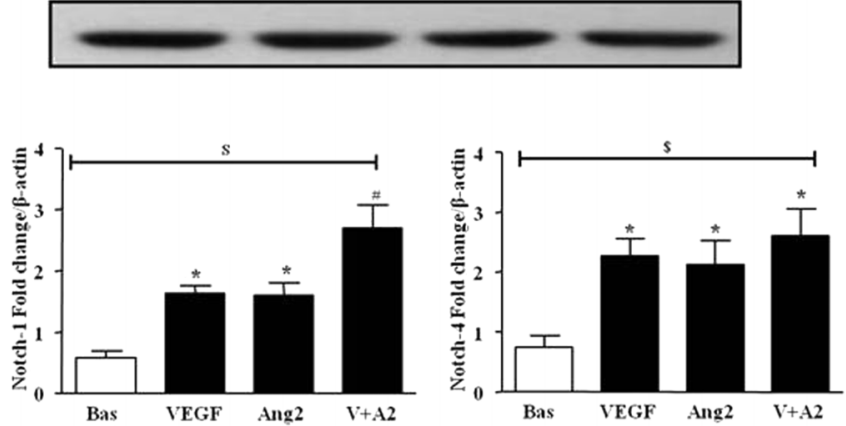

B

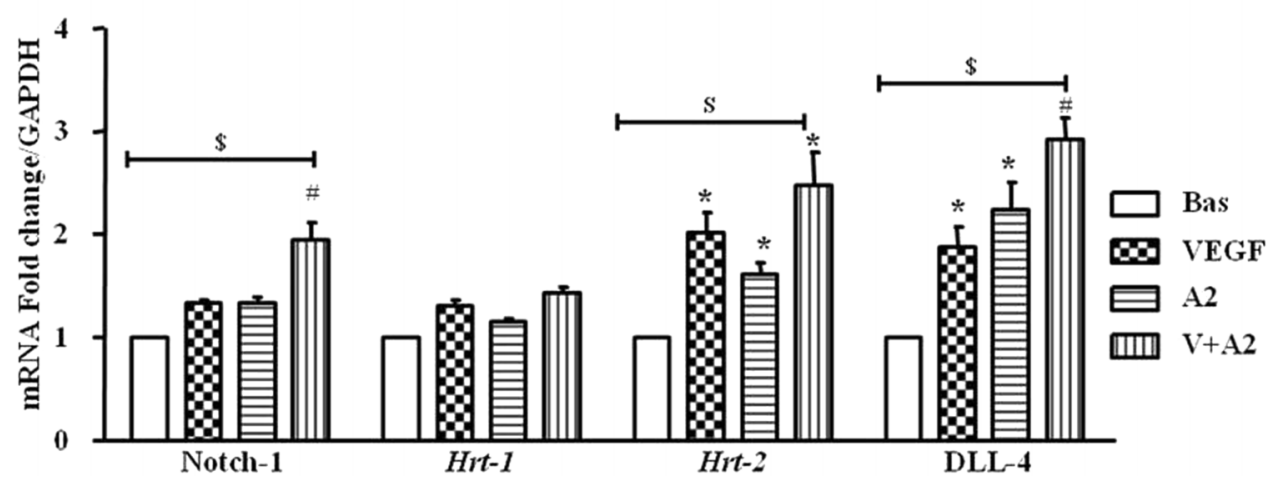

Figure 3 Vascular endothelial growth factor (VEGF) and angiopoietin 2 (Ang2) regulate the Notch signalling pathway in human microvascular endothelial cell (HMVEC). (A) Notch-1 intracellular domain (Notch-1 IC) and Notch-4 IC protein expression was examined in HMVEC following stimulation with VEGF $(20 \mathrm{ng} / \mathrm{ml})$ and Ang2 $(250 \mathrm{ng} / \mathrm{ml})$ alone or in combination for $24 \mathrm{~h}$ by Western blot. $\beta$-actin was used as loading control. Representative blot of $n=4$ experiments. (B) Notch-1, Hrt-1. Hrt-2 and DLL-4 mRNA expression was quantified in HMVEC following stimulation with VEGF $(20 \mathrm{ng} / \mathrm{ml})$ and Ang2 $(250 \mathrm{ng} / \mathrm{ml})$ alone or in combination for $24 \mathrm{~h}$ and normalised to Glyceraldehyde 3-phosphate dehydrogenase (GAPDH). Data is representative of three independent experiments. Values are expressed as mean $\pm S E M$ of $n=3$ experiments. ${ }^{\$} p<0.05$ significantly different for comparison of multiple parameters by ANOVA, ${ }^{*} p<0.05$ significantly different from basal, ${ }^{*} p<0.05$ significantly different from VEGF.

inhibited in the presence of Notch-1 siRNA, with no effect for scrambled control (figure 4A,B).

VEGF and Ang2 alone and in combination induced angiogenic tube formation, evident by an increase in the number of EC connecting branches (figure 5A). Notch-1 siRNA transfected HMVEC significantly inhibited VEGF/Ang2 induced tube formation, with no effect for scramble siRNA control. Similar effects were observed for HMVEC migration where DAPT inhibited VEGF/Ang2 combination induced EC migration (see online supplementary figure S3).

Notch signalling mediates VEGF/Ang2 induced angiogenesis and pro-inflammatory cytokine production in RA explants cultures

To assess the effect of the RA synovial microenvironment on EC function, synovial explants were stimulated with VEGF/ Ang2 \pm DAPT. RA synovial explant conditioned media treated with VEGF/Ang2 alone and in combination significantly increased HMVEC tube formation compared with control. This effect was markedly decreased in the presence of DAPT treated explants (figure $5 \mathrm{~B}$ ).
VEGF and Ang2 alone and in combination induced pro-MMP-2 and MMP-9 in RA synovial explants and HMVEC, an effect inhibited by DAPT (figure 6A). Finally, VEGF and Ang2 alone significantly induced IL- 6 and IL-8 expression from RA synovial explants with the VEGF/Ang2 combination further potentiated their expression. This effect was significantly inhibited by DAPT (figure 6B). DAPT also inhibited basal cytokine secretion, suggesting that it may effect other pathways that regulate endogenous cytokine secretion.

\section{DISCUSSION}

Angiogenesis and cell migration are critical in the pathogenesis of inflammatory diseases. Here, we demonstrate increased Notch-1 IC and Notch-4 IC protein expression in inflamed synovial tissue compared to OA tissue, and demonstrate that expression is further enhanced by VEGF/Ang2 stimulation of RA/PsA synovial explant cultures and HMVEC. Notch-1 receptor mRNA levels, downstream target genes $\mathrm{Hrt}-2$ and ligand DLL-4 were significantly increased by VEGF/Ang2 stimulation, alone and in combination. In RA synovial explants and HMVEC cultures, VEGF/Ang2 induced EC invasion, angiogenic 
A
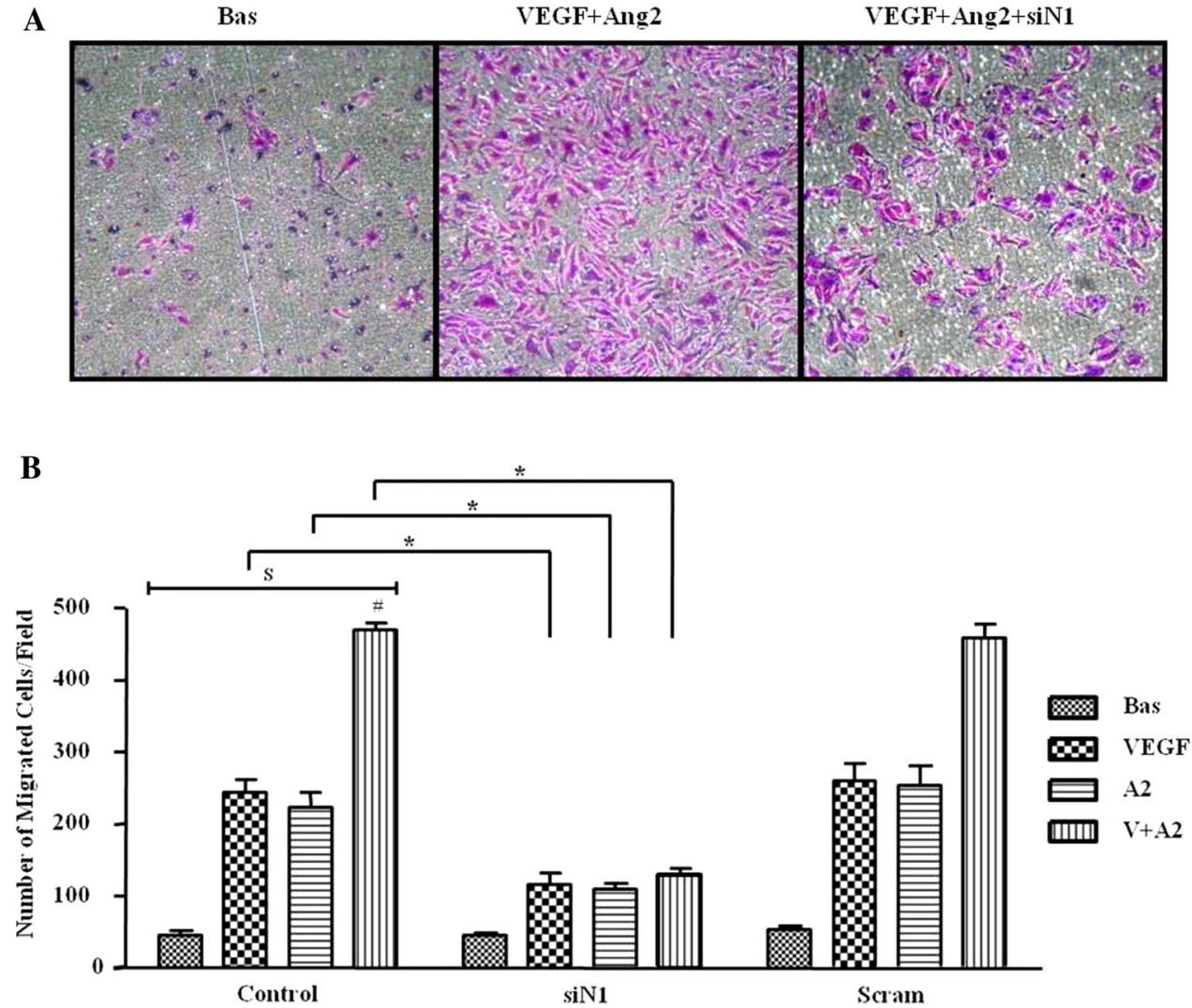

Figure 4 Vascular endothelial growth factor (VEGF) and angiopoietin 2 (Ang2)-induced cell invasion is dependent on Notch signalling. (A) Representative photomicrograph shows human microvascular endothelial cell (HMVEC) invasion under basal conditions (left panel), following VEGF/Ang2 stimulation (middle panel) and in the presence of Notch-1 siRNA (siN1, right panel). At $24 \mathrm{~h}$ invading cells attached to lower membrane were fixed ( $1 \%$ glutaraldehyde) and stained $(0.1 \%$ crystal violet) (hpf, magnification $\times 40)$. (B) Representative graphs quantifying non-transfected (control), transfected (Notch-1 or Scramble siRNA), HMVEC invasion following stimulation with VEGF (20 ng/ml), and Ang2 (250 ng/ml) alone or in combination for $16 \mathrm{~h}$. Data are expressed as mean \pm SEM of replicate experiments $(n=4)$. ${ }^{\$} p<0.05$ significantly different for comparison of multiple parameters by ANOVA, ${ }^{\#} \mathrm{p}<0.05$ significantly different from VEGF, ${ }^{*} \mathrm{p}<0.05$ significantly different.

tube formation, MMPs and cytokine expression, effects that were inhibited by Notch blockade. These data suggest that Notch signalling pathways mediate the pro-angiogenic effects of VEGF/Ang2 in IA.

Angiogenesis occurs early in the pathogenesis of inflammation. ${ }^{1-4}$ Distinct vascular morphology observed in IA or psoriasis plaques is related to expression of VEGF, Ang and their receptors. $5811 \quad 12$ Cytokines and toll-like receptor (TLRs) induce VEGF, Tie2, Ang1 and Ang2 in synovial fibroblasts and explant cultures. ${ }^{3} 726$ 55-58 VEGF mediates hypoxia-induced pro-angiogenic pathways in the inflamed joint. ${ }^{59} 60$ Furthermore, in a CIA model, blocking Tie2 activation inhibited arthritis-induced angiogenesis, receptor activator of nuclear factor Kappa-B ligand (RANKL) expression and bone erosion. $^{25} 61$ This process is dynamic, with studies demonstrating that it is the interactions between the VEGF and Ang-Tie2 pathways that are critical for new vessel formation, stability and survival. In the current study we showed increased expression of Notch-1 IC and Notch-4IC in inflamed synovium compared with OA, with highest expression observed in PsA vascular regions. Furthermore we demonstrated complementary interactions between VEGF and Ang2 acting via the Notch-1 signalling pathway to enhance EC invasion and tube formation, supporting the hypothesis of an unstable synovial vascular microenvironment. ${ }^{3} 59 \quad 6062$ The previously observed abnormal synovial vascular morphology, differential maturation status and coexpression of VEGF/Ang2 on synovial vessels, suggest that the dysfunctional synovial vessels may be regulated by VEGF/Ang2. 5062 This is consistent with previous reports in cancer models demonstrating that Ang2 blocks vessel stabilisation and induces capillary remodelling and new vessel sprouting in the presence of abundant VEGF ${ }^{18-21}$ Furthermore, Hashizume et al, demonstrated that inhibition of Ang2 and VEGF together slows tumour growth by inhibiting sprouting angiogenesis and proliferation. ${ }^{63}$

In this study, we demonstrate that VEGF and Ang2 alone increase Notch-1 IC and Notch-4 IC protein expression, downstream target genes and the ligand DLL-4, with the VEGF/Ang2 combination potentiating this effect further. In addition, VEGF/ Ang2 induced EC invasion, angiogenic tube formation and migration were inhibited by Notch-1 siRNA or DAPT. Furthermore, conditioned media from stimulated RA synovial explants induced EC tube formation, an effect inhibited by Notch blockade. Finally, we demonstrated that VEGF/Ang2 induced cytokine and matrix metalloproteinase (MMP) production was inhibited by DAPT in RA synovial explants, further suggesting Notch mediates VEGF/Ang2 pro-angiogenic effects in the inflamed synovial microenvironment. While the complementary functional interactions of VEGF/Ang2 in cancer models have been described and that VEGF can regulate Notch, this is the first study to show that Notch mediates the downstream functional effects of VEGF/Ang2 interactions in RA explants and HMVEC. In the conditioned media tube formation assays it is unclear which of the growth factors has a stronger 


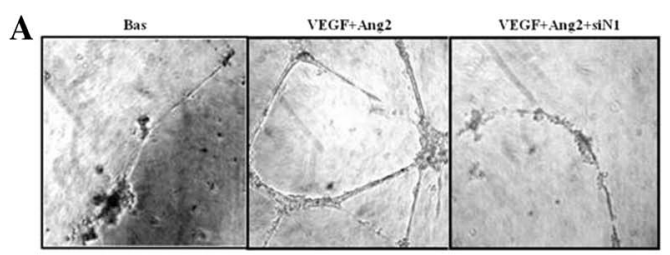

$\mathbf{B}$
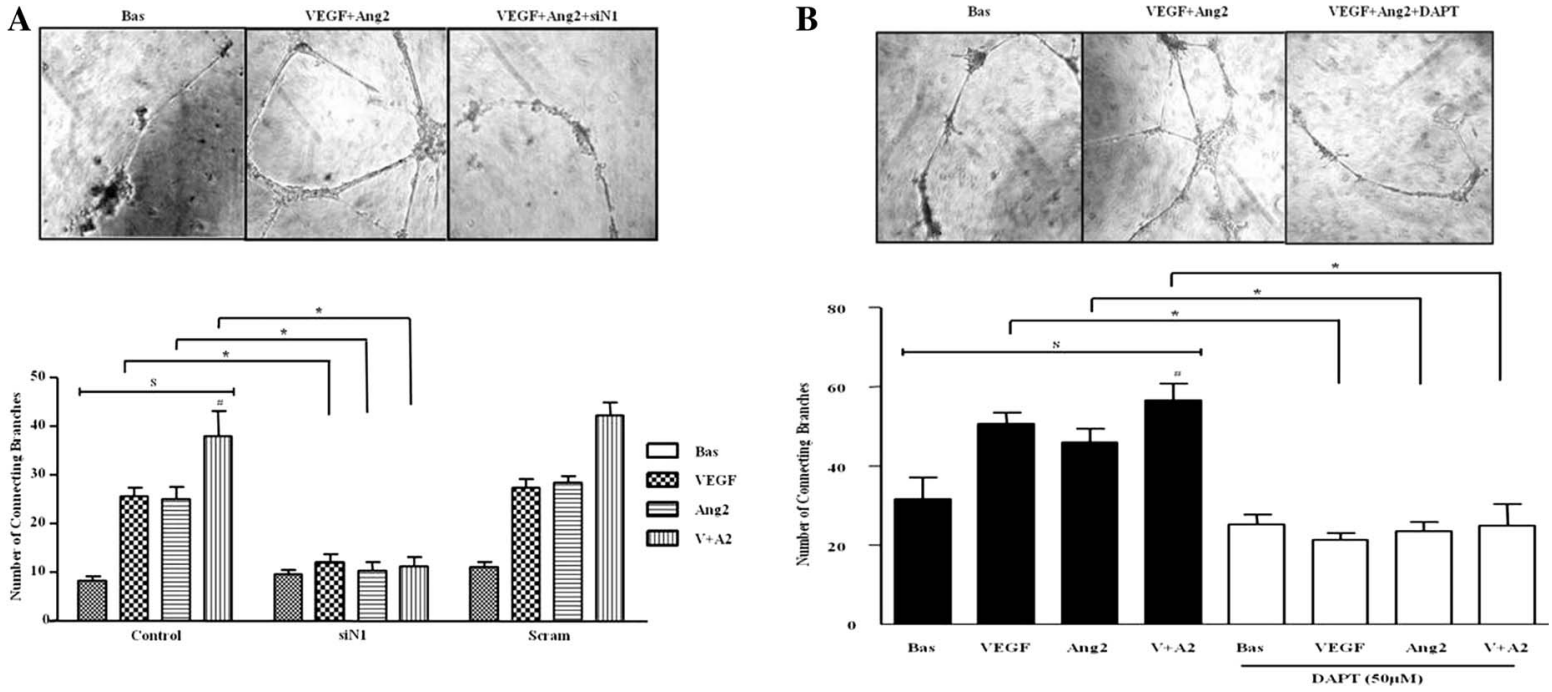

Figure 5 Notch signalling mediates vascular endothelial growth factor (VEGF) and angiopoietin 2 (Ang2)-induced cell tube formation. (A) Representative photomicrographs showing human microvascular endothelial cell (HMVEC) tube formation at baseline (left panel), following stimulation with VEGF and Ang2 (middle panel), and in the presence of Notch-1 siRNA transfection (right panel). Quantification of HMVEC tube formation following transfection with Notch-1 or Scramble siRNA following stimulation with VEGF ( $20 \mathrm{ng} / \mathrm{ml})$ and Ang2 (250 ng/ml) alone or in combination. Data are expressed as mean \pm SEM of replicate experiments $(n=4)$. (B) Representative photomicrograph shows HMVEC tube formation in basal conditioned media containing DMSO as vehicle control (left panel), conditioned media containing VEGF/Ang2 combination (middle panel), and in the presence of $50 \mu \mathrm{M} \mathrm{N}$-(N-(3,5-Difluorophenacetyl-L-alanly))-S-phenylglycine-t-Butyl Ester (DAPT) (right panel). Connecting branches numbers were quantified following stimulation with VEGF $(20 \mathrm{ng} / \mathrm{ml})$ and Ang2 $(250 \mathrm{ng} / \mathrm{ml})$ alone or in combination. Data are expressed as mean \pm SEM of replicate experiments $(n=4)$. ${ }^{\$} p<0.05$ significantly different for comparison of multiple parameters by ANOVA or by Friedman analysis, ${ }^{\#} \mathrm{p}<0.05$ significantly different from VEGF, ${ }^{*} \mathrm{p}<0.05$ significantly different.
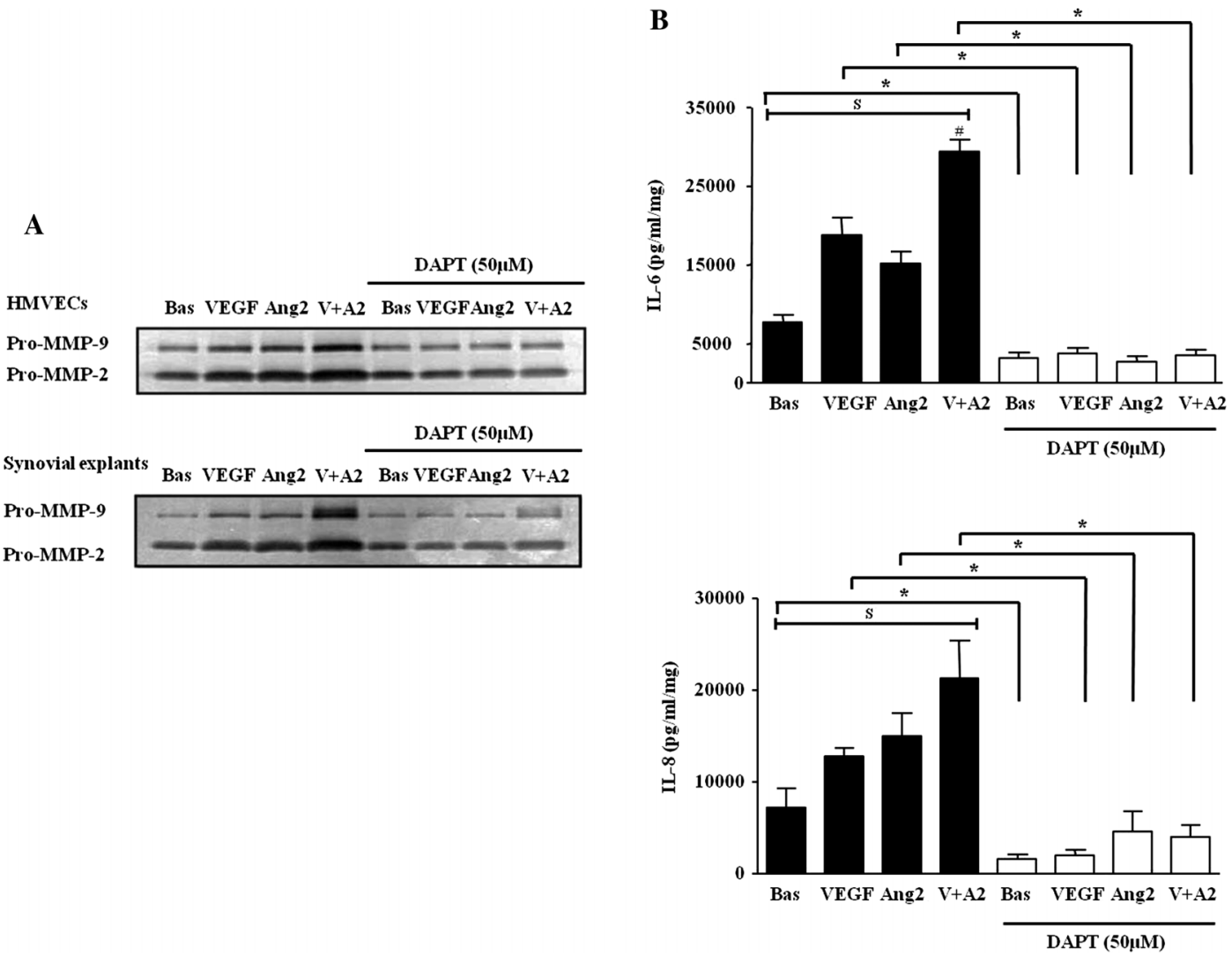

Figure 6 N-(N-(3,5-Difluorophenacetyl-L-alanly))-S-phenylglycine-t-Butyl Ester (DAPT) inhibits vascular endothelial growth factor (VEGF)/angiopoietin 2 (Ang2) induced MMPs and cytokines activities. (A) Representative in-gel zymography of pro-MMP-9 and MMP-2 activities (inverted for clarity) in human microvascular endothelial cells (HMVEC) and synovial explants following stimulation with VEGF (20 ng/ml) and Ang2 (250 ng/ml) alone or in combination in the presence of DAPT $(50 \mu \mathrm{M})$ or DMSO vehicle control. (B) Levels of IL-6 and IL-8 were assayed by ELISA in conditioned media with DAPT $(50 \mu \mathrm{M})$. Values are expressed as mean $\pm S E M$ of replicate experiments $(n=5)$. ${ }^{\$} p<0.05$ significantly different for comparison of multiple parameters by ANOVA or by Friedman analysis, ${ }^{\#} p<0.05$ significantly different from VEGF, ${ }^{*} p<0.05$ significantly different. 
effect, as this model maintains the architecture and cell-cell contact of the multiple cells in the synovial tissue, thus other downstream factors may also contribute to the observed functional effect. Previous studies have shown that the relative contribution of VEGF and Ang2 to their complementary action varies depending on the cell type and microenvironment, with studies showing complementary and inhibitory effects of Ang2 on VEGF, 196364 mechanisms which can also be dependent on the different vascular beds. ${ }^{65}$

Induction of DLL-4 expression in endothelial tip cells of sprouting vessels in response to VEGF resulting in activation of Notch in adjacent stalk cells has been demonstrated. ${ }^{66}$ Ang1/Tie2 signalling can induce Notch/DLL-4 through acutely transforming retrovirus (AKT8) in rodent $\mathrm{T}$ cell lymphoma-mediated activation of $\beta$-catenin. ${ }^{67}$ Notch-3 also cooperates with hypoxia-inducible factor (HIF) $1 \alpha$ to regulate Ang2 expression and neovascularisation under hypoxic conditions. ${ }^{68}$ Moreover, Notch-1 or Notch-4 mediate cyclic strain-induced angiogenesis and Ang1/Tie2 signalling, ${ }^{69}$ Consistent with the dysfunctional vascular morphology observed in inflamed joints, differential interactions of Notch with specific ligands has been shown to result in abnormal vessel branching, stability and morphology. ${ }^{13}$ Moreover, Notch signalling promotes intergrin/focal adhesion kinase (FAK) mediated pathways, which are known to be overexpressed in the inflamed synovium ${ }^{71}$ and promote EC branching/sprouting, vacuolation and lumen formation. ${ }^{72-76}$

Finally, we demonstrate that Notch mediates VEGF/Ang2 induced IL-6 and IL-8 in synovial explants. The observed inhibitory effect of DAPT on basal cytokine secretion also suggests that Notch-1 mediates other pathways involved in regulating endogenous cytokine secretion. This is supported by studies showing Notch signalling can regulate $T$ cell differentiation in RA patients and mediate cytokine production from RA synovial fibroblasts and T helper cells. ${ }^{44}{ }^{46}$ Notch inhibition downregulates Th17 and Th1 responses in a Giant Cell Arthritis model. ${ }^{77}$ Furthermore DAPT can inhibit cytokine/chemokine expression from dendritic cells (DC) and T cells ${ }^{78}$ and can inhibit IL-6 secretion from RA fibroblast-like synoviocytes (FLS). ${ }^{79}$ Thus, in addition to regulating vascular morphology, Notch signalling may also mediate VEGF/Ang2 induced cytokine profiles in the joint, further exacerbating the inflammatory response and joint destruction.

Beneficial effects of Notch signalling blockade include inducing tumour cell apoptosis, suppressing neuroblastoma cell growth and differentiation, ${ }^{80-82}$ In contrast, this therapeutic approach may conversely accelerate tumour metastasis and invasion, ${ }^{83} 84$ suggesting that vessel stabilisation, normalisation and improvement of oxygenation are key determinants of outcome. ${ }^{85}$ Studies also demonstrate Notch signalling is engaged in collagen II (CII)-specific Th1-type and Th17-type expansion, and suggest selective inhibition of Notch signalling pathways as potential therapeutic strategies for the treatment of RA. ${ }^{46}$

In conclusion, this is the first study to show that VEGF/ Ang2 induced pro-angiogenic/inflammatory mechanisms are mediated by Notch signalling pathways in the inflamed joint, further supporting the concept of developing therapeutic targets to the VEGF/Ang2-Notch axis in the treatment of IA.

\footnotetext{
Acknowledgements This work was supported by the Health Research Board, Ireland.

Contributors All authors contributed to this manuscript. UF had full access to all of the data in the study and takes responsibility for the integrity of the data and the accuracy of the data analysis. Study conception and design; Acquisition of data; Analysis and interpretation of data: WG, CS, CW, PR, JMC, DJV, UF.
}

Funding Health Research Board, Ireland.

Competing interests None.

\section{Patient consent Obtained.}

Ethics approval This study was conducted with the approval of the St. Vincent's University Hospital ethics committee.

Provenance and peer review Not commissioned; externally peer reviewed.

Open Access This is an Open Access article distributed in accordance with the Creative Commons Attribution Non Commercial (CC BY-NC 3.0) license, which permits others to distribute, remix, adapt, build upon this work non-commercially, and license their derivative works on different terms, provided the original work is properly cited and the use is non-commercial. See: http://creativecommons.org/licenses/by-nc/3.0/

\section{REFERENCES}

1. Akil M, Amos RS. ABC of rheumatology. Rheumatoid arthritis-l: clinical features and diagnosis. BMJ 1995;310:587-90.

2. Folkman J, D'Amore PA. Blood vessel formation: what is its molecular basis? Cell 1996;87:1153-5.

3. Koch AE. Angiogenesis as a target in rheumatoid arthritis. Ann Rheum Dis 2003;62 (Suppl 2):iï0-7.

4. Reece RJ, Canete JD, Parsons WJ, et al. Distinct vascular patterns of early synovitis in psoriatic, reactive, and rheumatoid arthritis. Arthritis Rheum 1999;42:1481-4.

5. Fearon U, Griosios K, Fraser A, et al. Angiopoietins, growth factors, and vascular morphology in early arthritis. J Rheumatol 2003;30:260-8.

6. Koch AE, Harlow LA, Haines GK, et al. Vascular endothelial growth factor. A cytokine modulating endothelial function in rheumatoid arthritis. J Immunol 1994;152:4149-56.

7. Scott BB, Zaratin PF, Colombo A, et al. Constitutive expression of angiopoietin-1 and -2 and modulation of their expression by inflammatory cytokines in rheumatoid arthritis synovial fibroblasts. J Rheumatol 2002;29:230-9.

8. Canete JD, Pablos JL, Sanmarti R, et al. Antiangiogenic effects of anti-tumor necrosis factor alpha therapy with infliximab in psoriatic arthritis. Arthritis Rheum 2004;50:1636-41.

9. Frye CA, Yocum DE, Tuan $\mathrm{R}$, et al. An in vitro model for studying mechanisms underlying synoviocyte-mediated cartilage invasion in rheumatoid arthritis. Pathol Oncol Res 1996;2:157-66.

10. Rosengren S, Corr M, Boyle DL. Platelet-derived growth factor and transforming growth factor beta synergistically potentiate inflammatory mediator synthesis by fibroblast-like synoviocytes. Arthritis Res Ther 2010;12:R65.

11. Braverman IM, Yen A. Ultrastructure of the capillary loops in the dermal papillae of psoriasis. J Invest Dermatol 1977;68:53-60.

12. Markham T, Mullan R, Golden-Mason L, et al. Resolution of endothelial activation and down-regulation of Tie2 receptor in psoriatic skin after infliximab therapy. J Am Acad Dermatol 2006;54:1003-12.

13. Cordiali-Fei P, Trento E, D’Agosto G, et al. Decreased levels of metalloproteinase-9 and angiogenic factors in skin lesions of patients with psoriatic arthritis after therapy with anti-TNF-alpha. J Autoimmune Dis 2006;3:5.

14. Veale D, Yanni G, Rogers $S$, et al. Reduced synovial membrane macrophage numbers, ELAM-1 expression, and lining layer hyperplasia in psoriatic arthritis as compared with rheumatoid arthritis. Arthritis Rheum 1993;36:893-900.

15. Ferrara N, Davis-Smyth T. The biology of vascular endothelial growth factor. Endocr Rev 1997:18:4-25.

16. Suri C, Jones PF, Patan $\mathrm{S}$, et al. Requisite role of angiopoietin-1, a ligand for the TIE2 receptor, during embryonic angiogenesis. Cell 1996;87: 1171-80

17. Suri C, McClain J, Thurston G, et al. Increased vascularization in mice overexpressing angiopoietin-1. Science 1998;282:468-71.

18. Maisonpierre PC, Suri C, Jones PF, et al. Angiopoietin-2, a natural antagonist for Tie2 that disrupts in vivo angiogenesis. Science 1997;277:55-60.

19. Asahara T, Chen D, Takahashi T, et al. Tie2 receptor ligands, angiopoietin-1 and angiopoietin-2, modulate VEGF-induced postnatal neovascularization. Circ Res 1998;83:233-40.

20. Holash J, Maisonpierre PC, Compton D, et al. Vessel cooption, regression, and growth in tumors mediated by angiopoietins and VEGF. Science 1999;284:1994-8.

21. Zagzag D, Hooper A, Friedlander DR, et al. In situ expression of angiopoietins in astrocytomas identifies angiopoietin-2 as an early marker of tumor angiogenesis. Exp Neurol 1999;159:391-400.

22. Uchida T, Nakashima M, Hirota Y, et al. Immunohistochemical localisation of protein tyrosine kinase receptors Tie-1 and Tie-2 in synovial tissue of rheumatoid arthritis: correlation with angiogenesis and synovial proliferation. Ann Rheum Dis 2000;59:607-14.

23. Shahrara S, Volin MV, Connors MA, et al. Differential expression of the angiogenic Tie receptor family in arthritic and normal synovial tissue. Arthritis Res 2002;4:201-8.

24. Malik NM, Jin $\mathrm{P}$, Raatz $\mathrm{Y}$, et al. Regulation of the angiopoietin-Tie ligand-receptor system with a novel splice variant of Tie1 reduces the severity of murine arthritis. Rheumatology (Oxford) 2010;49:1828-39. 
25. Chen Y, Donnelly E, Kobayashi H, et al. Gene therapy targeting the Tie2 function ameliorates collagen-induced arthritis and protects against bone destruction. Arthritis Rheum 2005:52:1585-94.

26. Saber T, Veale DJ, Balogh E, et al. Toll-like receptor 2 induced angiogenesis and invasion is mediated through the Tie2 signalling pathway in rheumatoid arthritis. PLoS One 2011;6:e23540

27. Milner LA, Bigas A. Notch as a mediator of cell fate determination in hematopoiesis: evidence and speculation. Blood 1999;93:2431-48.

28. Artavanis-Tsakonas S, Rand MD, Lake RJ. Notch signaling: cell fate control and signal integration in development. Science 1999;284:770-6.

29. Gridley T. Notch signaling in vascular development and physiology. Development 2007:134:2709-18.

30. Iso T, Hamamori Y, Kedes L. Notch signaling in vascular development. Arterioscler Thromb Vasc Biol 2003:23:543-53.

31. Sullivan DC, Bicknell R. New molecular pathways in angiogenesis. Br J Cancer 2003:89:228-31.

32. Liu ZJ, Shirakawa T, Li Y, et al. Regulation of Notch1 and DII4 by vascular endothelial growth factor in arterial endothelial cells: implications for modulating arteriogenesis and angiogenesis. Mol Cell Biol 2003;23:14-25.

33. Armulik A, Abramsson A, Betsholtz C. Endothelial/pericyte interactions. Circ Res 2005;97:512-23.

34. Li L, Huang GM, Banta $A B$, et al. Cloning, characterization, and the complete 56.8-kilobase DNA sequence of the human NOTCH4 gene. Genomics 1998;51:45-58.

35. Uyttendaele H, Marazzi G, Wu G, et al. Notch4/int-3, a mammary proto-oncogene, is an endothelial cell-specific mammalian Notch gene. Development 1996;122:2251-9.

36. Knust E, Dietrich U, Tepass U, et al. EGF homologous sequences encoded in the genome of Drosophila melanogaster, and their relation to neurogenic genes. EMBO J 1987;6:761-6.

37. Fleming RJ, Scottgale TN, Diederich RJ, et al. The gene Serrate encodes a putative EGF-like transmembrane protein essential for proper ectoderma development in Drosophila melanogaster. Genes Dev 1990;4:2188-201.

38. Lindsell CE, Shawber CJ, Boulter J, et al. Jagged: a mammalian ligand that activates Notch1. Cell 1995;80:909-17.

39. Weinmaster G. Notch signaling: direct or what? Curr Opin Genet Dev 1998;8:436-42.

40. Mumm JS, Kopan R. Notch signaling: from the outside in. Dev Biol 2000;228:151-65.

41. Davis RL, Turner DL. Vertebrate hairy and enhancer of split related proteins: transcriptional repressors regulating cellular differentiation and embryonic patterning Oncogene 2001;20:8342-57.

42. Ando K, Kanazawa S, Tetsuka T, et al. Induction of Notch signaling by tumor necrosis factor in rheumatoid synovial fibroblasts. Oncogene 2003;22:7796-803.

43. Ishii H, Nakazawa M, Yoshino S, et al. Expression of notch homologues in the synovium of rheumatoid arthritis and osteoarthritis patients. Rheumatol Int 2001;21:10-14.

44. Kijima M, Iwata A, Maekawa Y, et al. Jagged1 suppresses collagen-induced arthritis by indirectly providing a negative signal in CD8+ T cells. J Immunol 2009; 182:3566-72

45. Nakazawa M, Ishii $\mathrm{H}$, Aono $\mathrm{H}$, et al. Role of Notch-1 intracellular domain in activation of rheumatoid synoviocytes. Arthritis Rheum 2001;44:1545-54.

46. Jiao Z, Wang W, Xu H, et al. Engagement of activated Notch signalling in collagen II-specific T helper type 1 (Th1)- and Th17-type expansion involving Notch3 and Delta-like1. Clin Exp Immunol 2011:164:66-71.

47. $\mathbf{N g} \mathbf{C T}$, Biniecka M, Kennedy A, et al. Synovial tissue hypoxia and inflammation in vivo. Ann Rheum Dis 2010;69:1389-95.

48. Arnett FC, Edworthy SM, Bloch DA, et al. The American Rheumatism Association 1987 revised criteria for the classification of rheumatoid arthritis. Arthritis Rheum 1988;31:315-24.

49. Taylor W, Gladman D, Helliwell P, et al. Classification criteria for psoriatic arthritis: development of new criteria from a large international study. Arthritis Rheum 2006; 54:2665-73

50. Feliers D, Chen $\mathrm{X}$, Akis $\mathrm{N}$, et al. VEGF regulation of endothelial nitric oxide synthase in glomerular endothelial cells. Kidney Int 2005;68:1648-59.

51. Dunk C, Shams M, Nijjar S, et al. Angiopoietin-1 and angiopoietin-2 activate trophoblast Tie-2 to promote growth and migration during placental development. Am J Pathol 2000;156:2185-99.

52. Gao W, Sweeney C, Connolly $M$, et al. Notch-1 mediates hypoxia-induced angiogenesis in rheumatoid arthritis. Arthritis Rheum 2012;64:2104-13.

53. Kennedy A, Ng CT, Chang TC, et al. Tumor necrosis factor blocking therapy alters joint inflammation and hypoxia. Arthritis Rheum 2011;63:923-32.

54. Connolly $\mathbf{M}$, Veale DJ, Fearon U. Acute serum amyloid A regulates cytoskeletal rearrangement, cell matrix interactions and promotes cell migration in rheumatoid arthritis. Ann Rheum Dis 2011;70:1296-303

55. Szekanecz Z, Koch AE. Endothelial cells in inflammation and angiogenesis. Curr Drug Targets Inflamm Allergy 2005;4:319-23.

56. Cho ML, Jung Y0, Moon YM, et al. Interleukin-18 induces the production of vascular endothelial growth factor (VEGF) in rheumatoid arthritis synovial fibroblasts via AP-1-dependent pathways. Immunol Lett 2006;103:159-66.

57. Honorati MC, Neri S, Cattini L, et al. Interleukin-17, a regulator of angiogenic factor release by synovial fibroblasts. Osteoarthritis Cartilage 2006;14:345-52.
58. Cho ML, Ju JH, Kim HR, et al. Toll-like receptor 2 ligand mediates the upregulation of angiogenic factor, vascular endothelial growth factor and interleukin-8/CXCL8 in human rheumatoid synovial fibroblasts. Immunol Lett 2007;108:121-8.

59. Akhavani MA, Madden L, Buysschaert I, et al. Hypoxia upregulates angiogenesis and synovial cell migration in rheumatoid arthritis. Arthritis Res Ther 2009; 11:R64.

60. Kennedy A, $\mathrm{Ng} \mathrm{CT}$, Biniecka $\mathrm{M}$, et al. Angiogenesis and blood vessel stability in inflammatory arthritis. Arthritis Rheum 2010;62:711-21.

61. DeBusk LM, Chen Y, Nishishita T, et al. Tie2 receptor tyrosine kinase, a major mediator of tumor necrosis factor alpha-induced angiogenesis in rheumatoid arthritis. Arthritis Rheum 2003;48:2461-71.

62. Izquierdo $\mathbf{E}$, Canete JD, Celis $\mathrm{R}$, et al. Immature blood vessels in rheumatoid synovium are selectively depleted in response to anti-TNF therapy. PLoS One 2009; 4:e8131.

63. Hashizume H, Falcon BL, Kuroda T, et al. Complementary actions of inhibitors of angiopoietin-2 and VEGF on tumor angiogenesis and growth. Cancer Res 2010;70:2213-23.

64. Peters S, Cree IA, Alexander R, et al. Angiopoietin modulation of vascular endothelial growth factor: Effects on retinal endothelial cell permeability. Cytokine 2007:40:144-50

65. Oshima $\mathbf{Y}$, Oshima $\mathrm{S}, \mathrm{Nambu} \mathrm{H}$, et al. Different effects of angiopoietin-2 in different vascular beds: new vessels are most sensitive. FASEB J 2005;19:963-5.

66. De Smet F Segura I, De Bock K, et al. Mechanisms of vessel branching: filopodia on endothelial tip cells lead the way. Arterioscler Thromb Vasc Biol 2009;29:639-49.

67. Zhang J, Fukuhara S, Sako K, et al. Angiopoietin-1/Tie2 signal augments basal Notch signal controlling vascular quiescence by inducing delta-like 4 expression through AKT-mediated activation of beta-catenin. J Biol Chem 2011;286:8055-66.

68. Liu H, Zhang W, Kennard S, et al. Notch3 is critical for proper angiogenesis and mural cell investment. Circ Res 2010;107:860-70.

69. Morrow D, Cullen JP, Cahill PA, et al. Cyclic strain regulates the Notch/CBF-1 signaling pathway in endothelial cells: role in angiogenic activity. Arterioscler Thromb Vasc Biol 2007;27:1289-96.

70. Johnson BA, Haines GK, Harlow LA, et al. Adhesion molecule expression in human synovial tissue. Arthritis Rheum 1993;36:137-46.

71. Connolly M, Marrelli A, Blades M, et al. Acute serum amyloid A induces migration, angiogenesis, and inflammation in synovial cells in vitro and in a human rheumatoid arthritis/SCID mouse chimera model. J Immunol 2010:184:6427-37.

72. Bayless KJ, Davis GE. The Cdc42 and Rac1 GTPases are required for capillary lumen formation in three-dimensional extracellular matrices. J Cell Sci 2002;115:1123-36.

73. Chapados R, Abe K, Ihida-Stansbury K, et al. ROCK controls matrix synthesis in vascular smooth muscle cells: coupling vasoconstriction to vascular remodeling. Circ Res 2006;99:837-44.

74. Philippova M, Ivanov D, Allenspach R, et al. RhoA and Rac mediate endothelial cell polarization and detachment induced by T-cadherin. FASEB $J$ 2005; 19:588-90.

75. Davis GE, Bayless KJ. An integrin and Rho GTPase-dependent pinocytic vacuole mechanism controls capillary lumen formation in collagen and fibrin matrices. Microcirculation 2003;10:27-44.

76. Hoang MV, Whelan MC, Senger DR. Rho activity critically and selectively regulates endothelial cell organization during angiogenesis. Proc Natl Acad Sci USA 2004;101:1874-9.

77. Piggott K, Deng J, Warrington K, et al. Blocking the NOTCH pathway inhibits vascular inflammation in large-vessel vasculitis. Circulation 2011;123:309-18.

78. Perez-Cabezas B, Naranjo-Gomez M, Bastos-Amador P, et al. Ligation of Notch receptors in human conventional and plasmacytoid dendritic cells differentially regulates cytokine and chemokine secretion and modulates Th cell polarization. $\mathrm{J}$ Immunol 2011;186:7006-15.

79. Jiao Z, Wang W, Ma J, et al. Notch signaling mediates TNF-alpha-induced IL-6 production in cultured fibroblast-like synoviocytes from rheumatoid arthritis. Clin Dev Immunol 2012:2012:350209.

80. Curry CL, Reed LL, Golde TE, et al. Gamma secretase inhibitor blocks Notch activation and induces apoptosis in Kaposi's sarcoma tumor cells. Oncogene 2005;24:6333-44.

81. Ghaleb AM, Aggarwal G, Bialkowska AB, et al. Notch inhibits expression of the Kruppel-like factor 4 tumor suppressor in the intestinal epithelium. Mol Cancer Res 2008; 6:1920-7.

82. Ferrari-Toninelli G, Bonini SA, Uberti D, et al. Targeting Notch pathway induces growth inhibition and differentiation of neuroblastoma cells. Neuro Oncol 2010;12:1231-43.

83. Ebos JM, Lee CR, Cruz-Munoz W, et al. Accelerated metastasis after short-term treatment with a potent inhibitor of tumor angiogenesis. Cancer Cell 2009;15:232-9.

84. Paez-Ribes M, Allen E, Hudock J, et al. Antiangiogenic therapy elicits malignant progression of tumors to increased local invasion and distant metastasis. Cancer Cell 2009:15:220-31.

85. Jain RK. Normalization of tumor vasculature: an emerging concept in antiangiogenic therapy. Science 2005;307:58-62 